\title{
Vegetation Remnants: Their Role in Nature Conservation
}

Over much of the world, 'clearing' of land has removed most of the natural vegetation, leaving only small remnants of the original ecosystems. Areas that previously contained important biological resources have been among those cleared, so that many plant and animal species have become restricted to remnants, which may consequently hold a vital store of genetic material. Unlike large areas in which natural processes continue to function, the smaller remnants are often subject to a variety of disturbances that commonly cause a decrease in their number of species.

A recent workshop convened at Busselton in Western Australia, by the Commonwealth Scientific and Industrial Research Organization and the W.A. Department of Conservation and Land Management, addressed the question of how best to manage vegetation remnants to enhance their conservation value. The workshop identified remnants as having the following attributes:

- they provide representative or selected samples of ecosystems that were once more extensive;

- they often contain landscape and biotic elements, including rare species, that are not otherwise protected;

- they can provide multiple samples of species throughout their former range, thus sustaining genetic variability;

- they provide stepping-stones and/or corridors for many species, and enhance gene-flow;

- they are important to surrounding lands by affecting hydrology, nutrient cycling, and erosion;

- they have aesthetic, educational, and recreational, values; and

- they help to create a public awareness of Nature and Nature conservation, especially amongst rural people.

The major conclusions regarding the conservation of remnants concerned the needs for management and research, and for improved integration of these two activities to make more efficient use than hitherto of the scarce resources that are allocated to Nature conservation generally.

Few remnants are large enough to sustain ecological processes at such rates as occurred before fragmentation, and many are subject to disturbances originating in the surrounding cleared land. Management of some kind is therefore always required. Objectives for management should be clearly defined. These should be arranged in a hierarchy from the world level, through the regional, to specific reserve level, and from overall management objectives to those concerning the use of specific management techniques. The public should always be involved in defining these objectives, and in developing the plans for their implementation, as public participation is crucial.

Properly defined programmes of relevant research provide the basis for effective management of remnants. Research should include autecological studies, work on population genetics, and studies of the dynamics of ecosystems. Some of the single species under investigation should include 'umbrella' species - species that appeal to the public and politicians and, if conserved, will also protect remnants supporting a wide range of other organisms.

Research workers should communicate their findings in the scientific literature and in popular publications, and should provide realistic procedures for land managers to follow. To help achieve this, land managers, planners, and research workers, must work closely together at all levels.
As most management proceeds in the absence of adequate research knowledge, the proper monitoring of the results of management activities can contribute much to the understanding of the ecosystems that are being managed. Monitoring programmes should be long-term, as changes in many important ecological processes can only be detected over a scale of decades or even centuries. Monitoring has for too long been considered third-rate science. Appropriate design and execution, combined with hypothesis-testing, can, however, make long-term monitoring attractive to a wider scientific community. Monitoring must not be too expensive or complicated. It must be relevant, and some studies must be designed so that they can be carried out by local managers and naturalists.

Most statements on Nature conservation highlight the need to conserve gene-pools. However, it appears that in relation to conserving remnant populations, too little is known about the effects of inbreeding, minimum viable population sizes, genetic drift, 'bottlenecks', mutation, etc. There is a clear need to improve genetic theory and to document actual genetic events in small populations of species from a broad phylogenetic spectrum.

Natural vegetation, including remnants, is being destroyed world-wide at an alarming rate. Many remnants have no legal security even to protect their conservation values. The workshop unanimously concluded that more effort must go into protecting remnants and, wherever possible, into expanding them by land acquisition. Education of the public is essential to enable politicians to achieve this goal.

The workshop challenges scientists and naturalists who understand the values of native vegetation, to spend a significant part of their time (say, 10\%) helping the public and politicians to understand the role of remnants of native vegetation in Nature conservation - so that these valuable repositories of the world's heritage will not be lost for ever.

\author{
DENIS SAUNDERS \\ Commonwealth Scientific \& Industrial \\ Research Organization (CSIRO) \\ Division of Wildlife \& Rangelands Research \\ LMB No. 4 \\ P.O. Midland \\ Western Australia 6056 \\ Australia,
}

Graham ARNOLD

(Ibid.),

ANDREW BuRbIDGE

Wildlife Research Centre

Department of Conservation

$\&$ Land Management

P.O. Box 51

Wanneroo

Western Australia 6065

Australia,

$$
\&
$$

Angas Hopkins

Department of Conservation

\& Land Management

P.O. Box 51

Wanneroo

Western Australia 6065

Australia. 